\title{
Three Dimensional Stress Analysis of a Helical Gear Drive with Finite Element Method
}

\author{
M. Gh. KHOSROSHAHI, A. M. FATTAHI* \\ *Department of Mechanical Engineering, Tabriz Branch, Islamic Azad University, Tabriz, Iran, \\ E-mail: a.fattahi@iaut.ac.ir

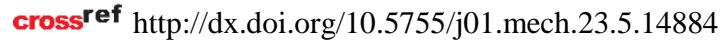

\section{Nomenclature}

$E$ - young's modulus, $\quad v$-poison's ratio, $f$ - friction coefficient, $T$ - transmitted torque, $P_{\max }$ - largest surface pressure, $F$ - force pressing the two cylinders together, $b_{\mathrm{o}}$ - half width of rectangular contact area, $l$ - length of cylinder, $v_{1}, v_{2}$ - Poison's ratio of the two contacting cylinders, $E_{1}, E_{2}$ - Young's modulus of the two contacting cylinders, $d_{1}, d_{2}$ - diameters of the two contacting cylinders, $\sigma_{c}$ - contact stress, $Z_{E}$ - elastic coefficient, $W^{t}$ - tangential transmitted load, $d_{p}$ - pitch circle diameter, $F_{\mathrm{o}}$ - face width, $\phi_{\mathrm{t}}$ - pressure angle, transverse, $m_{G}$ - speed ratio, $N_{i}$ - number of teeth, $\sigma$ - bending stress, $K_{o}$ - overload factor, $K_{V}$ - dynamic factor, $K_{S}$ - size factor, $b$ - net face width of narrowest member, $m_{t}$ - transverse metric module, $K_{H}$ - load-distribution factor, $K_{B}$ - rim-thickness factor, $Y_{J}$ - geometry factor for bending strength, $d_{\omega 1}$ - pitch diameter of the pinion, $Z_{R}$ surface condition factor for pitting resistance, $Z_{1}$ - geometry factor for pitting resistance.

\section{Introduction}

Helical gears are widely used as power transmitting gears between parallel or crossed shafts or between a shaft and a rack by meshing teeth that lie along a helix at an angle to the axis of the shaft. In this kind of gears, the dynamic load and the noise level experienced during the operation are minimized. The helical gear differs from the spur gear in that its teeth are twisted along a helical path in the axial direction. It resembles the spur gear in the plane of rotation, but in the axial direction it is as if there were a series of staggered spur gears. This design brings forth a number of different features relative to the spur gear, two of the most important being as follows: firstly, tooth strength is improved because of the elongated helical wrap around tooth base support; secondly contact ratio is increased due to the axial tooth overlap. However, involute helical gears are very sensitive to axial misalignments, causing discontinuous transmission errors (TE) and edge contacts, resulting in noise and vibration [1]. The teeth of helical gears are usually modified to attain a localized point contact and to avoid edge contacts [2]. Recently, Litvin proposed the concept of tooth surface modification to obtain a pre-designed parabolic TE as well as a localized bearing contact of the gear set [3]. This concept of tooth modification has been applied to the generation of various kinds of gearing, such as spur gears, helical gears and worm gear drives [4-7].

Gears can fail in many different ways. The general types of failure modes (in decreasing order of frequency) include fatigue, impact fracture; wear and stress rupture [8].
Misalignment is probably the most common, single cause of failure, due to misalignment; the pinion does not mesh properly with the gear during operation, and this lead to a high stress concentration at the surface of gears. The misalignment also leads to severe wear and excessive heat generation at the mating surfaces [9]. Also, damage to and failures of gears in gearbox can and do occur as a direct or indirect result of lubrication problems [8-10].

The contact stress and fillet stress on gears, which cause pitting and bending failure, have attracted much attention [10-12]. The gear contact stresses derived from tooth contact forces and geometry are very important for determining gear pitting, i.e. life performance [13]. Generally, there are two types of surface contact fatigue, namely, pitting and spalling. Pitting originates from small, surface or subsurface initial cracks, which grow under repeated contact loading. Pitting is a three-dimensional phenomenon and strongly depends on contact surface finish, material microstructure and operating conditions, such as type of contact, loading, misalignment, lubrication problems, temperature, etc. [9].

Spalling, in general, is not considered an initial mode of failure but rather a continuation or propagation of pitting and rolling contact fatigue. Although pitting appears as shallow craters at contact surfaces, spalling appears as deeper cavities at contact surfaces $[8,10,14]$ as shown in Figs. 1 and 2. The classical tooth bending-fatigue failure is that occurs and progresses in the area designed to receive the maximum bending stress [8]. Bending fatigue breakage starts with a crack in the root section and progresses until the tooth or part of it breaks off. It can be recognized by a fatigue "eye" or focal point of the break [15]. Tooth foundation flexibility was found to have an essential role in contact load sharing between the meshing teeth, whereas contact flexibility plays only a minor role. Deformations are calculated according to the Hertz line contact theory, otherwise assuming rigid tooth behaviour [13]. Some studies are made by slicing the helical gear to a series of spur gears and treating these slices as spur gears [16].

Finite-element-based calculation models are widely accepted for calculating structural deformations and stresses in spur and helical gears in the case of concentrated loads [13]. Coy and Chao studied finite element grid size dimensions to cover the Hertzian contact[17]. Du et al. [18] and Arafa et al. [19] later enhanced contact modeling as a part of structural analysis by using gap elements for the calculation of spur gear deformation [18-19]. Vedmar separated structural and contact analysis by combining the finite element method and the Weber \& Banaschek deformation formulae to study the contact behavior of involute helical gears[20]. Pimsarn and Kazerounian avoided the use of contact elements by introducing a fast pseudo-interference 
method for the calculation of mesh stiffness in the case of a spur gear pair [21]. Kawalec et al. presented a comparative analysis of tooth-root strength evaluation methods used within ISO and AGMA standards and verifying them with developed models and simulations using the finite element method [22]. Therefore, finite element analysis (FEA), which can involve complicated tooth geometry, is now a popular and powerful analysis tool to determine tooth deflections and stress distributions [23-26].

In this research an FEM package, ANSYS, capable of contact analysis was employed to determine the stress distribution on a pair of contact gear. To do this two identical helical gears are meshing at five contact positions on the teeth when the pinion hole inner surface is displaced tangentially. Contact and bending stresses are calculated by the finite element method (FEM) and are then compared with the stress results obtained from AGMA standard and Hertz theory.

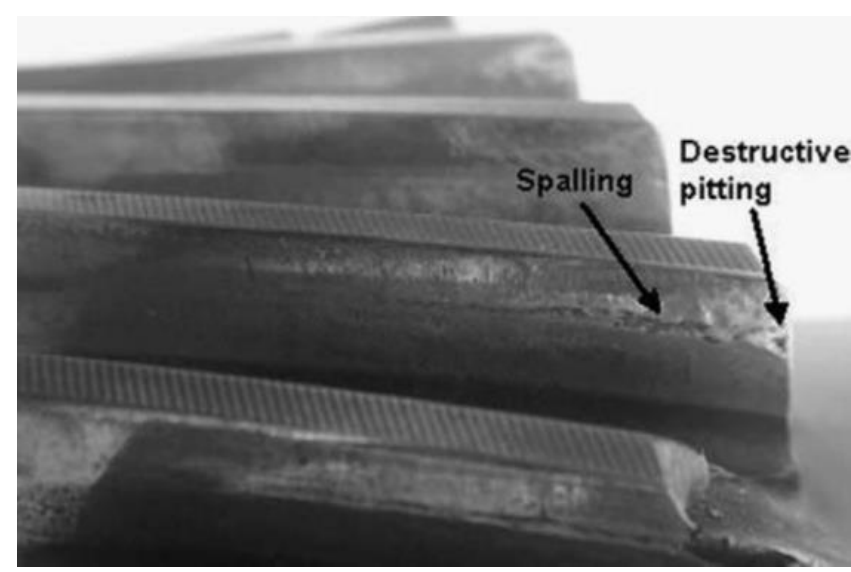

Fig. 1 Photograph of the pitted gear teeth. Note, spalling and destructive pitting at one end of tooth at vicinity of the pitch line [9]

\section{Overview of various plate theories}

In order to model the meshing of helical gears, two identical standard gears with specified geometry (see Table 1) was considered in this research. For the sake of simplicity, both thePinion and the gear in the drive have the same geometry in the numerical example [27]. A CAD package Solid Works is used to develop the geometric models of the helical gear drive. This package has a special gear design module. After the whole geometry of the gears were built, they had to be exported in a suitable way to FEA environment, the commercially available finite element codeANSYS. Data exchange was accomplished by SAT standard with a good final accuracy of the models, due to the common geometrical database between the source and the destination code, and to the nature of the exported model. Due to the complexity of the tooth geometry, it is difficult to apply mapped meshing for the helical gear drive model. It is necessary to divide the body into some individual units of 6-sided volumes so that the software can implement the mapped mesh.

To facilitate the convergency different types of elements has been used for the contacting surfaces andthe rest ofthe model, respectively. The model consists of one set of SOLID95 elements for the half of the contacting teeth and another set of SOLID45 for the rest of the model as shown in Figs. 3 - 5. Then these FE meshes are tied together with a Lagrange Multiplier Technique to ensure the compatibility.In the contacting face of the teeth, SOLID95 elements were used as this element gives much accurate results compared to SOLID45 elements. However, using SOLID95 elements in the entire model was avoided as they needed much processing time in comparison with SOLID45 elements. Furthermore, contact areas of gears are being meshed by TARGE170 and CONTA174 elements. These contact elements, which sit on solid elements, allow pressure to be transferred between the two contact teeth, but without them the contacting teeth penetrate each other. All elements have three degrees of freedom (DOF) at each node: translations in the $\mathrm{x}, \mathrm{y}$, and $\mathrm{z}$ directions [28]. The total number of elements was 89472 with 138798 nodes.

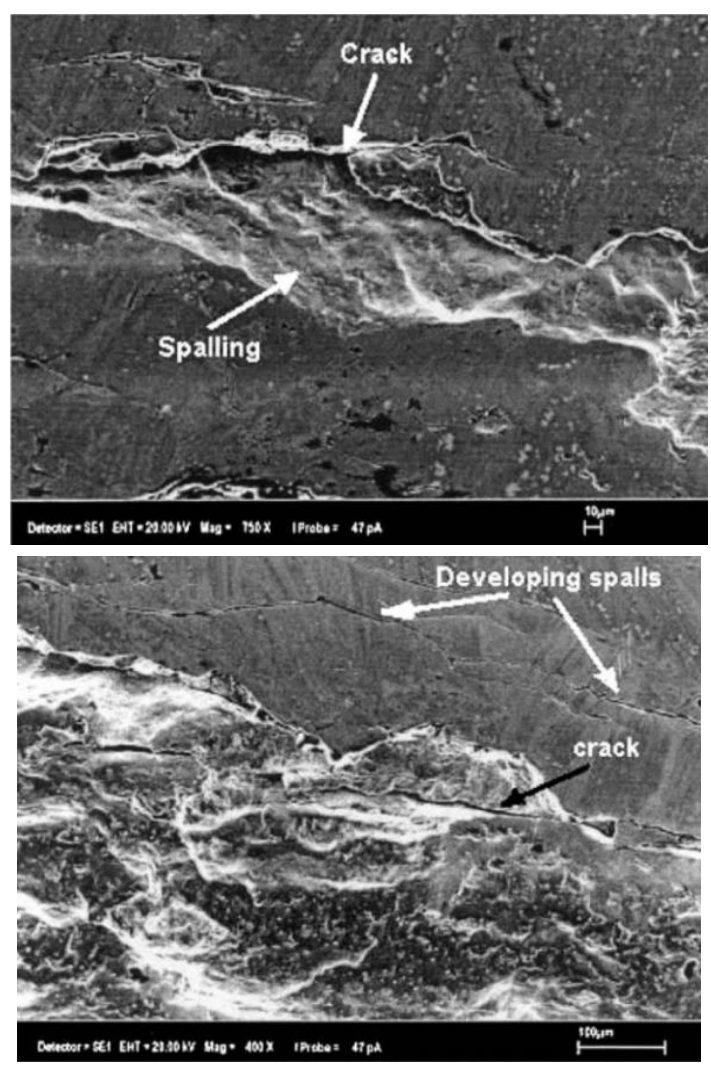

Fig. 2 SEM micrograph showing two damaged area at the pitch line at the different magnification [9]

Table 1

Geometrical data of gears

\begin{tabular}{|l|l|}
\hline Description & Values \\
\hline Pitch circle diameter $/ \mathrm{mm}$ & 89.798 \\
\hline Face width $/ \mathrm{mm}$ & 38.1 \\
\hline Module, normal $/ \mathrm{mm}$ & 8.438 \\
\hline Number of teeth & 10 \\
\hline Pressure angle, normal & $18.5^{\circ}$ \\
\hline Helix angle & $20^{\circ}$ \\
\hline
\end{tabular}

In the FEM model a carbon steel has been chosen for gear and pinion materials with mechanical properties of $E=207000 \mathrm{MPa}$ and $v=0.292$. In order to include friction effect, the model was run with friction coefficient of $f=0.08$ [29]. Concerning the boundary condition of the model, all 
the three DOF of the nodes located on the hole area of the gear (the lower one) are fixed. Also all the nodes located on pinion's hole surface along $\mathrm{x}$ direction are fixed. In order to rotate the pinion, the nodes on two opposite lines along $\mathrm{x}$ axis at the hole surface are displaced tangential to the hole surface $(\Delta=0.04 \mathrm{~mm})$ as shown in Fig. 5 . This boundary condition is realistic as the pinion is rotated through its power shaft via the hole inner surface. The transmitted torque (for the given rotation of the hole surface) was calculated from the displaced nodes reactions in the FEM models.

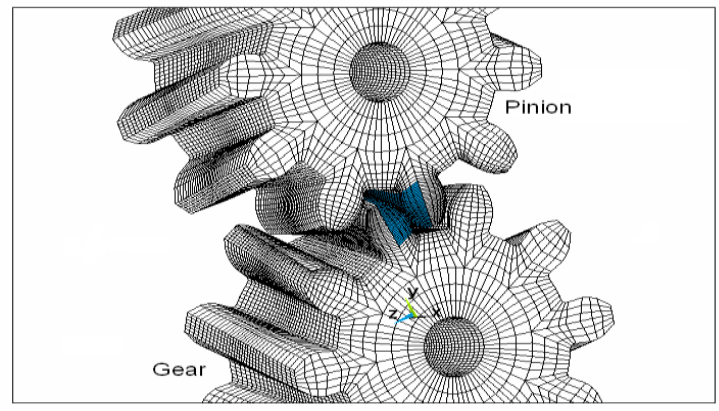

Fig. 3 FE model

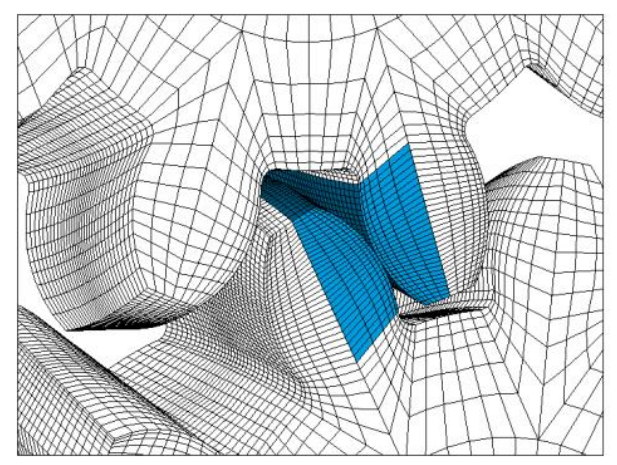

Fig. 4 Mesh densities at contacting teeth

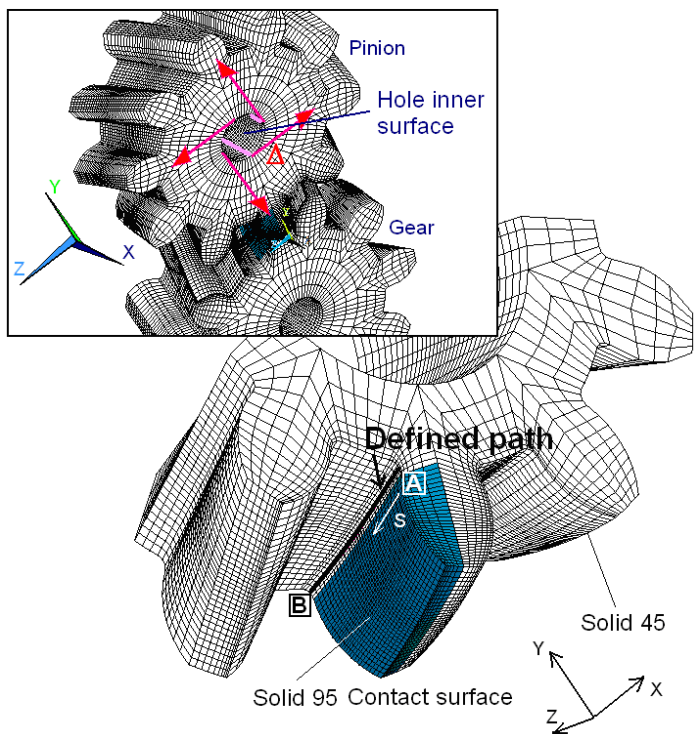

Fig. 5 Element types and tangential displacement of hole inner surface nodes

The FEM-based contact model gives a reasonable approximation of contact parameters when the mesh size is fine enough to retain the contacting structure shapes, so meshing (engaged) gears require small element size, i.e. a large number of elements to avoid element dimensional distortion [13]. In order to obtain converged results (mesh size independent results), the FEM model was initially run using a coarse mesh but was then refined several times until the results converged. The study has been carried out for the investigation of actual meshing simulation, contact behavior and the boundary condition of a helical gear set. The regions where stress concentration may occur, such as the fillets and possible contact areas, are discredited by a finer mesh (Figs. 3 and 4). In this paper to obtain stress distributions at different locations (positions), the meshing (engaged) gears were engaged in five position of the teeth flank (see position A to E in Fig. 6.
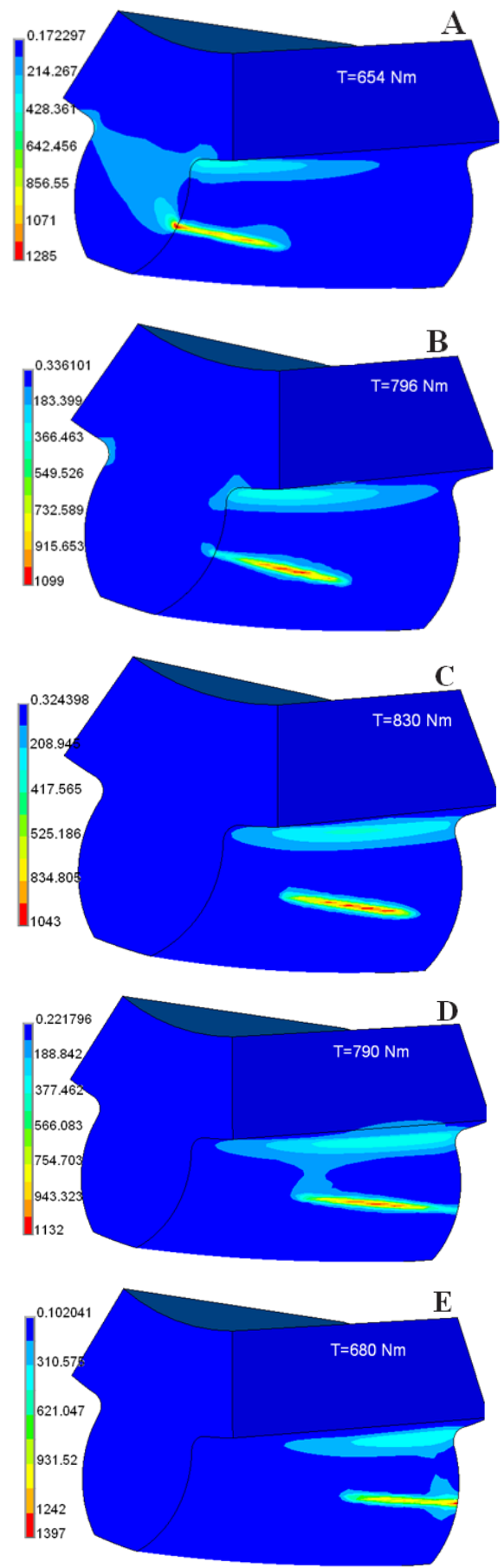

Fig. 6 Von-Mises stress (MPa) distribution on the pinion and calculated torques (for $\Delta=0.04 \mathrm{~mm}$ ) for different positions of the contacting tooth 


\section{Numerical example}

\section{1. Contact stress}

The FEM stress analysis for contact stress variations versus different torques has been illustrated in Fig. 7 for the case when one pair of teeth had been meshed (engaged) together. The result of contact stresses for Hertz theory and the AGMA standard for model (position) C (see Fig. 6) are calculated in Appendix A and Appendix B haveshown in Table 2 for thetransmitted torque of 297 N.m in pinion. As Fig. 7 shows the contact stress calculated from the Hertz theory and the AGMA standard are very close but the FEM results are bigger than the two other methods, because, gear contact is not purely Hertzian [30].

\section{2. Bending stress}

Generally, the bending stresses in the fillets of the two contacting teeth sides are considered tensile stresses, and those in the fillets of the opposite, unloaded teeth sides, are considered compressive stresses.

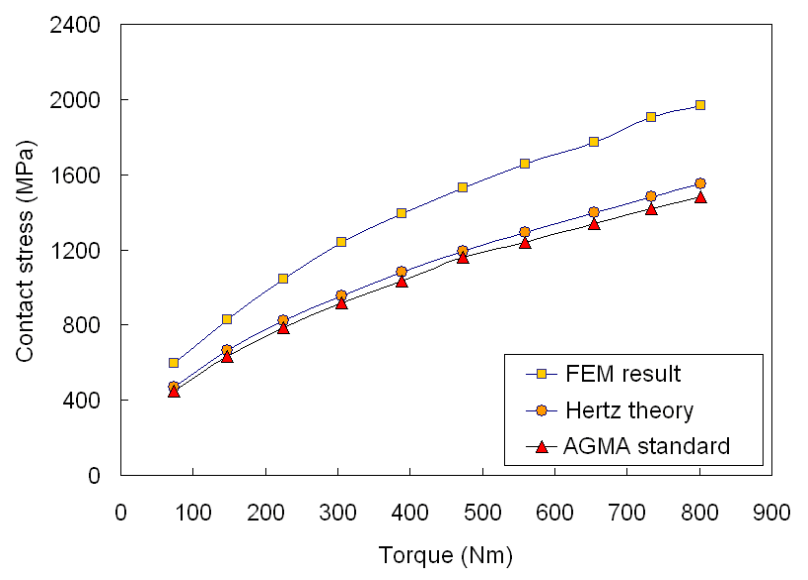

Fig. 7 Contact stress results obtained from FEM, Hertz theory and AGMA standard for model C

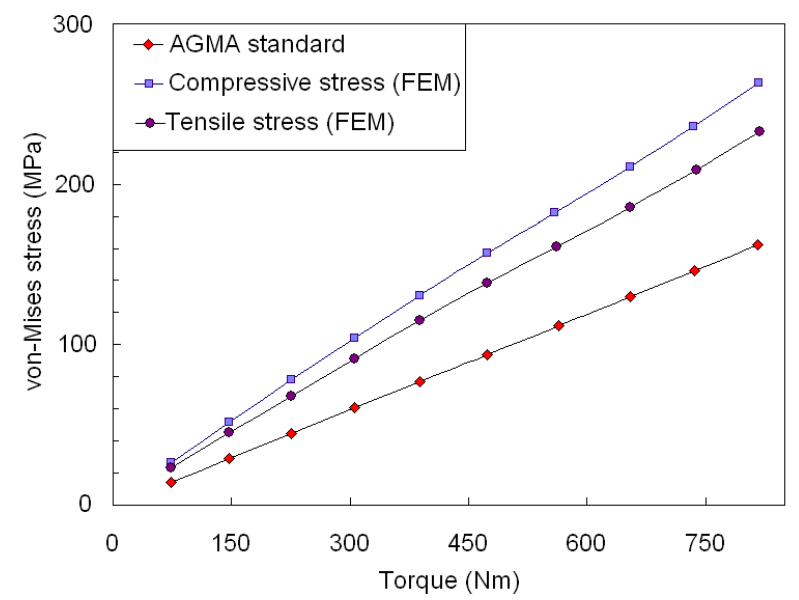

Fig. 8 Bending stress obtained from AGMA standard and FEM model for model $\mathrm{C}$

For analysis of the pinion tooth, five contact positions were considered, then the models are solved and the results are shown as contours in Fig. 6. The relation between von-Mises stress at the tooth root (which is very close to the bending tensile and compressive stress values at either side of the tooth) and transmitted torque is shown as graphs in Fig. 8 for the contact position model C.

Table 2

Contact stress calculated with different methods for the transmitted torque of $T=297 \mathrm{Nm}$ (model C)

\begin{tabular}{|l|l|}
\hline Contact stress calculation methods & Values \\
\hline FEM /MPa & 1229 \\
\hline Hertz theory (see Eq. (A.3))/ MPa & 936 \\
\hline AGMA standard (see Eq. (B.2))/MPa & 901 \\
\hline
\end{tabular}

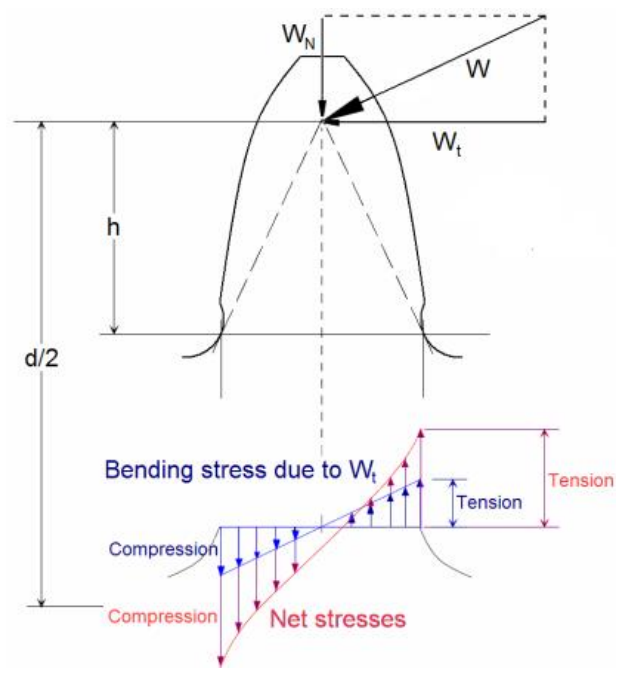

Fig. 9 Effect of radial component of contacting force to increase compressive stress and reduce the tensile stress at the tooth root

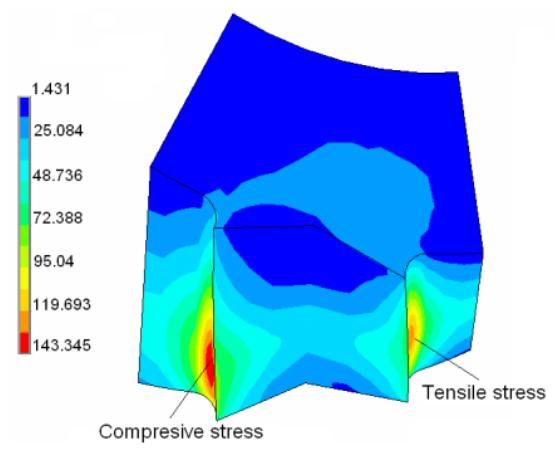

Fig. 10 Bending stress (von-Mises, MPa) distributionalong the pinion's fillet for torque $T=297$ N.m in model C

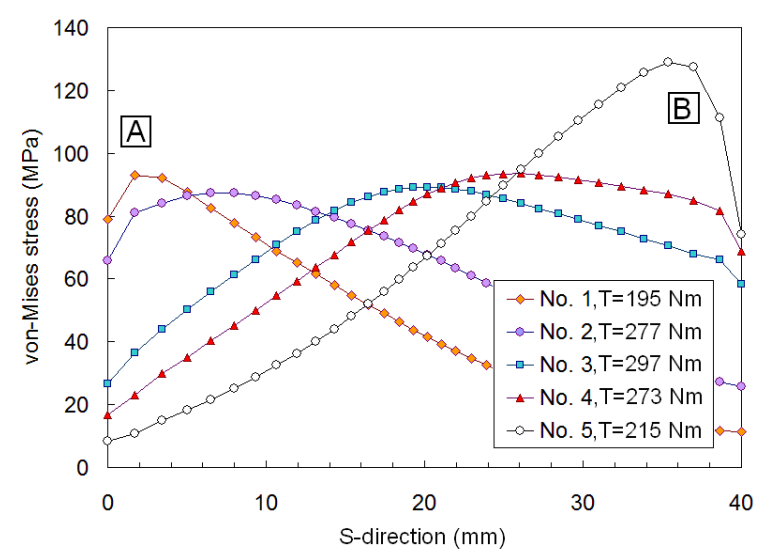

Fig. 11 Bending tensile stress (von-Mises) along the pinion's fillet (see Fig. 7 for S-direction) 


\section{Discussion}

In this paper the stress analysis of two identical helical gears has been carried out using FEM Package. The analysis was conducted for five positions of teeth meshing locations.For these five contacting positions the von-Mises stress contours were shown in Fig. 6 for the same tangential displacement of the pinion hole inner surface nodes $(\Delta=0.04 \mathrm{~mm})$. As the results show this stress is larger in models (positions) $\mathrm{A}$ and $\mathrm{C}$ than others while their transmitted torques are lower.

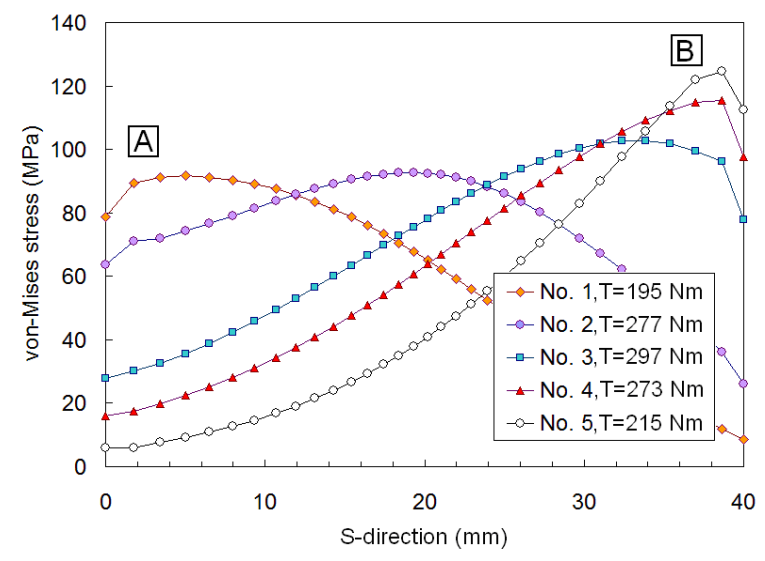

Fig. 12 Bending compressive stress (von-Mises) along the pinion's fillet (see Fig. 7 for S-direction)

One of the reasons of this larger von-Mises stress is short contact area at the beginning and end of tooth engagement. As Fig. 6 shows location of contact in models B and $\mathrm{D}$ are almost the same from the middle of the tooth face width, also the transmitted torques are close to each other. The ideal tooth meshing happens at the middle of flank (model D) where the magnitude of the stress is lower and the transmitted torque is higher. This can be due to larger contact area at the middle of the flank (it must be noted that every time only one pair of teeth is meshing). High stress concentration at position model A can cause early crack creation and consequently pitting phenomenon, as shown in Fig. 1. The area immediately above or below the pitch line is very susceptible to pitting [8].

The variation of bending stress versus transmitted torques has shown in Fig. 10 for FEM and AGMA methods. As the graph indicates this variation is linear and the compressive bending stress in the fillet of opposite side is larger than tensile bending stress in the fillet of contacting side. This is due to the radial compressive component of the contacting force of the meshing teeth, as shown in Fig. 9. The bending stress is the average of von-Mises stresses at the eight integration points of elements (as used in [2]) located at fillet that are given in Table 3 for model $\mathrm{C}$ contact position when transmitted torque is $T=297 \mathrm{Nm}$.

As the results show there is much difference between FEM and AGMA standard results. This could be related to the following fact; firstly, AGMA uses only the transmitted (tangential) component of force (between the interacting teeth) see Fig. 9. Secondly, AGMA assumes uniform stress distribution through the tooth face width but the bending stress distribution is not uniform at this area as FEM results show (see Fig. 10) this is due the fact that the contact area occurs only at part of tooth face width. Thirdly,
AGMA uses $K_{f}$ (fatigue notch factor) in stead of $K_{t}$ (theoretical stress concentration factor) where $K_{f}$ is usually less than $K_{t .}$.

Figs. 11 and 12 illustrated tensile (von-Mises) and compressive (von-Mises) bending stresses at tooth face width for five contact positions for the same pinion hole inner surface rotation $(\Delta=0.016 \mathrm{~mm})$ respectively.

As Fig. 11 shows for model $C$ position, the bending stresses are distributed much evenly through the tooth face width than positions model $\mathrm{A}$ and $\mathrm{E}$. The maximum tensile stresses occur at the root radius on the active flank of the gear tooth (as shown in Fig. 10) failure from bending fatigue generally results from a crack originating in the root section of the gear tooth[8][31].

The contact stress obtained by FEM is larger than the Hertzian contact stress calculated from the Hertzian stress formulae (see Appendix A) and AGMA stress formulae (see Appendix B), as shown in Fig. 7 and Table 2. However, the variation of contact stresses is nonlinear with increasing torque and the curves are very similar. The result of Hertzian contact stress from the Hertzian stress formulae and AGMA stress formulae are very close. The lager magnitudes of contact stresses obtained from FEM are related to the smaller contact area (unlike the whole tooth face width engagement in the theoretical formulae) as shown in Fig. 6. The contour of shear stress Syz (the other two shear stresses are very small) for the engaged teeth under transmitted torque $T=297 \mathrm{Nm}$ for model $\mathrm{C}$ was shown in Fig. 13. As the Figure indicates the maximum shear stress value occurs somewhere under tooth surface. The distribution of shear stress Syz through the tooth thickness for contact position model $\mathrm{C}$ was shown in Fig. 16 for different torques for a given path (see Fig. 13). As the graphs represents the maximum shear stress occurs at the same place and slightly below the contact surface $(0.39 \mathrm{~mm})$ for all torques, this subject was also quoted in the literature [8][32][33]. The mechanism of crack initiation and fatigue crack growth is attributed to large shearing stresses, so fatigue crack starts at the location of maximum shear stress and then propagate with mixed modes to reach tooth surface [33].

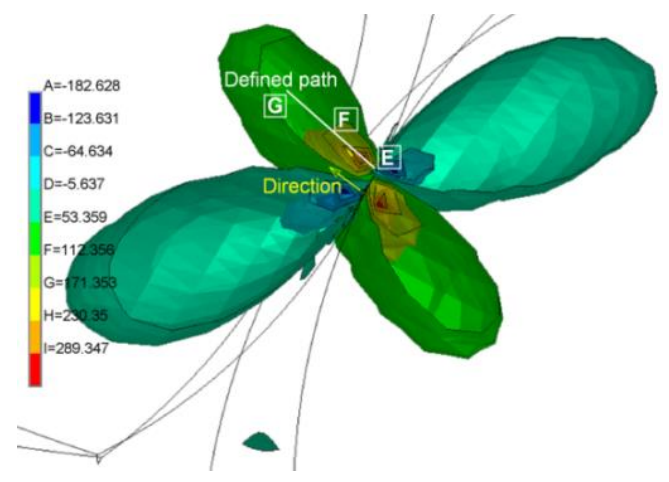

Fig. 13 Defined path at the section of the tooth with distribution of the shear stress (MPa) under torque $T=297 \mathrm{Nm}$ in model C

The extra shear stress in the case of sliding when added to that of the rolling often results in near-surface fatigue at the point of maximum shear below the surface (Fig. 15) [8]. It is the opinion of many authorities that this maximum shearstress is responsible for the surface fatigue failure of contacting elements. The explanation is that a 
crack originates at the point of maximum shear stress below the surface and progresses to the surface then due to the pressure of the lubricant wedges the chip loose [32].

3-D finite element simulations of contacting teeth have shown that the maximum value of von-Mises stress is slightly below the contact surface (in the place of maximum shear stress i.e. $0.39 \mathrm{~mm}$ below the teeth surface) asillustrated in Fig. 16.

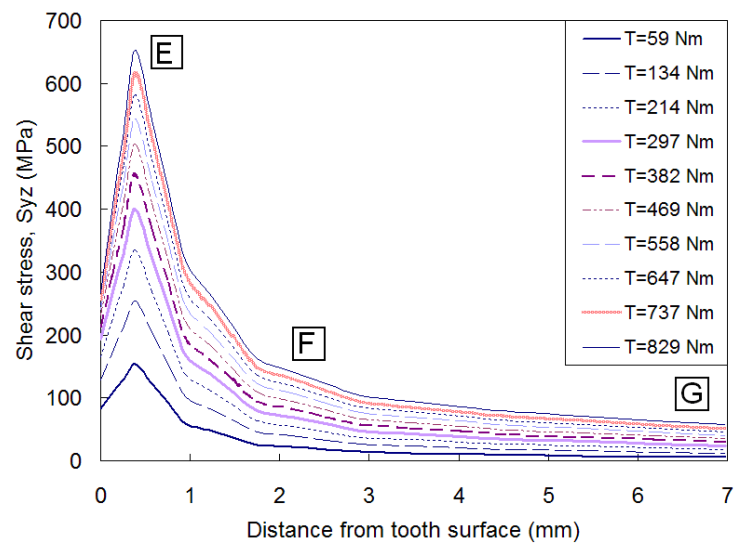

Fig.14 Shear stress distributions on the 11th transverse section counted from opposite $\mathrm{X}$ direction of the contact teeth under all torque in model $\mathrm{C}$ (see Fig. 13 for defined path

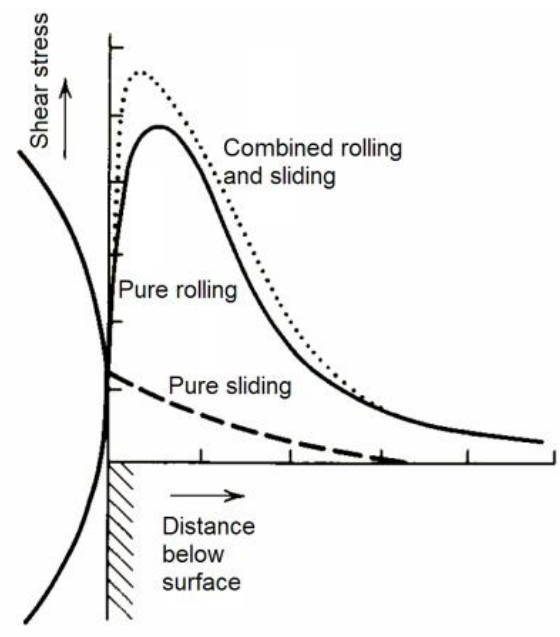

Fig. 15 Stress distribution in contacting surfaces due to rolling, sliding and combined effect [8]

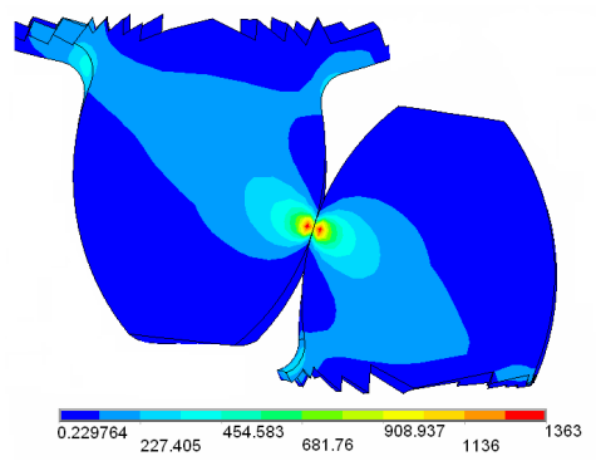

Fig. 16 Von-Mises stress (MPa) distribution on the 11th transverse section counted from opposite $\mathrm{X}$ direction of the contact teeth under torque $T=297 \mathrm{Nm}$ in model $\mathrm{C}$

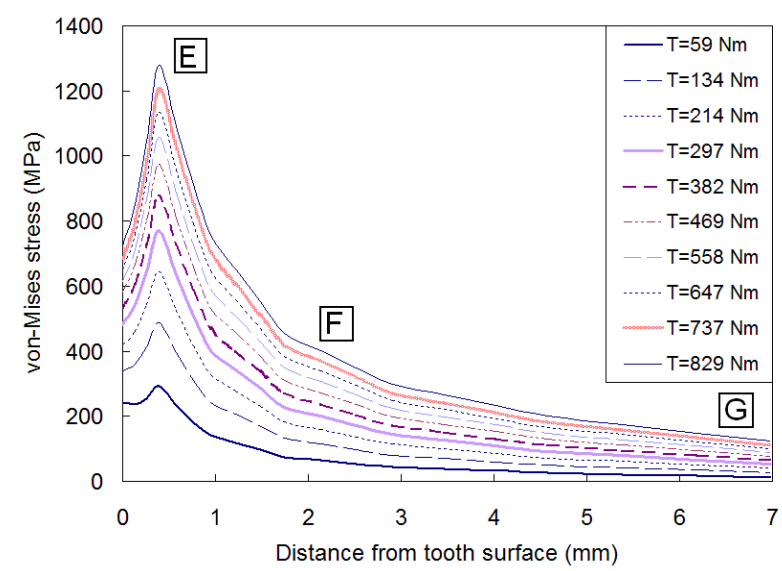

Fig. 17 Von-Mises stress distribution on the 11th transverse section counted from opposite $\mathrm{X}$ direction of the contact teeth under all torque in model $\mathrm{C}$ (see Fig. 15 for defined path)

The von-Mises stress distributions on the 11th transverse section counted from opposite $\mathrm{X}$ direction (Figs. 3-5) in the path shown in Fig. 13 for the contact teeth under all torques in model $\mathrm{C}$ were shown in the Fig. 17. The interesting result is that maximum of shear and von-Mises stresses increase with small rates for larger torques, this is the same for both shear and von-Mises stresses (see Fig. 14 and Fig. 17).

The variation of shear stress versus the distance from tooth surface (towards the tooth center line, see path EFG in Fig. 13, at the contact region) for the same tangential displacement of the pinion hole innernodes $(\Delta=0.016 \mathrm{~mm})$ and for five contact positions is shown in Fig. 18. As can been seen the location of maximum shear stress is similar for all contact positions. Also the maximum value of shear stress occurs at start and end of contact position because of the least contact area in models A and E (even though the transmitted torque is smaller).

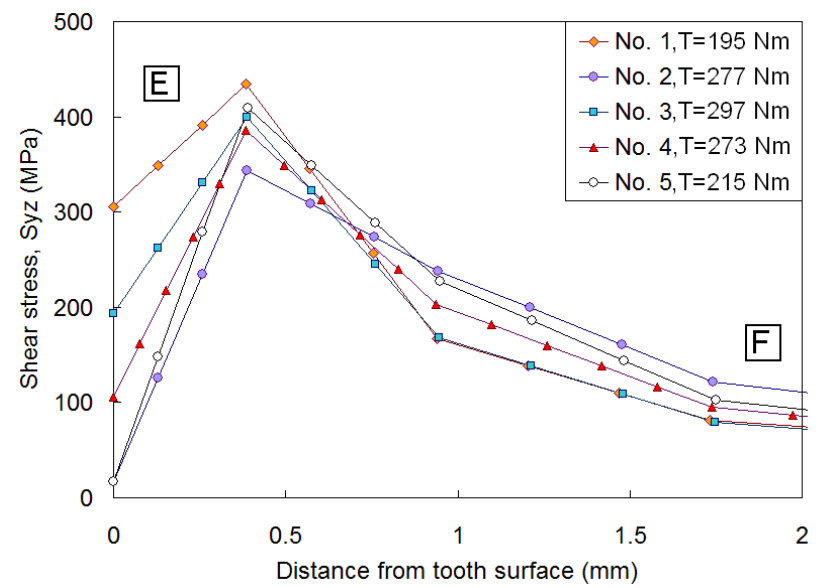

Fig. 18 Shear stress distribution on the critical places of transverse section of the contact tooth under calculated torques for all models (for the same $\Delta=$ $=0.016 \mathrm{~mm}$ )

The contact path for model $\mathrm{C}$ is shown in Fig. 19. In this figure the region of sticking and sliding is depicted. This path is conformable with experimental specimens. In the case of helical gears, the contact line is a diagonal one 
emerging as a point at the beginning of contact from a point low on the flank near the tooth root and gradually grows to a line of varying length up to the contact line passing through the tip of the first face of the gear tooth.

On further gear rotation, the length remains constant for some time and then diminishes gradually to a point at the tip of the last face where the contact ends. Thus, the contact line moves gradually along the whole range of the face width, covering the tooth flank and face [9]. However, because of the occurrence of elastic deformation (deflection) on the surface of loaded teeth and misalignment in service, contact occurs along narrow bands or in small areas instead of along the expected line contact [8][12].

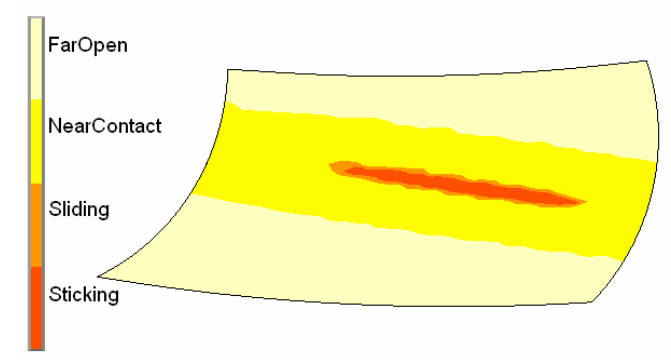

Fig. 19 Contact path in tooth surface in model C

\section{Conclusions}

1 The contact stress calculated by FEM is larger than the Hertzian contact stress obtained from the Hertzian stress formulae (see Appendix A) and AGMA stress formulae (see Appendix B).

2 According to the FEM result, the relation of contact stresses with torque is nonlinear, whereas this is linear for bending stresses.

3 According to the FEM result the distribution and magnitude of stresses is not the same at the tooth face width for different contact position when the pinion hole inner surface is displaced to the same amount. When tooth contact occurs at the middle of tooth face width the stress is much evenly distributed than when contact occurs at the beginning and end of the tooth face width.

4 The compressive bending stress in the fillet at the opposite side is larger than tensile bending stress in the fillet at contacting side.

5 The FEM results illustrate that contact position and applied load level (transmitted torque) do not have influence on the location of maximum shear and von-Mises stresses from the tooth surface.

6 Due to elastic deformation (deflection) of the loaded teeth, contact occurs along narrow bands or in small areas instead of along a line.

7 Contact occurs at two surfaces of mating teeth but von-Mises and maximum shear stresses slightly below the contact surface reaches a maximum value.

\section{Appendix A. Determination of Hertzian contact stress}

The instantaneous contact point of the gear tooth surfaces is spread over an elliptical area with the center of symmetry located at the theoretical contact point, due to the elasticity [2]. Surface fatigue failure can be occurred due to many repetitions of high contact stresses. To obtain an expression for the surface-contact stress, we shall employ the Hertz theory. In Eq. (A. 1) it was shown that the contact stress between two cylinders may be computed from the equation [32].

$$
P_{\max }=\frac{2 F}{\pi b_{0} l},
$$

and $b_{o}$ is obtained from the equation

$$
b_{0}=\sqrt{\frac{2 F}{\pi l} \frac{\left.\left.\left[\left(1-v_{1}^{2}\right)\right) / E_{1}\right]+\left[\left(1-v_{2}^{2}\right) / E_{2}\right]\right)}{\left(1 / d_{1}\right)+\left(1 / d_{2}\right)}},
$$

where $v_{1}, v_{2}, E_{1}$ and $E_{2}$ are the elastic constants, $d 1$ and $d 2$ are the diameters of the two contacting cylinders. However, the adopted Hertezian law for gearing in order to calculate the surface compressive stress (Hertzian stress) can be determined as follow [28].

$$
\sigma_{t}=Z_{E} \sqrt{\frac{W^{t}}{d_{P} F_{o}\left(\frac{\cos \Phi_{t} \sin \Phi_{t}}{2} \frac{m_{G}}{m_{G}+1}\right)}}
$$

AGMA defines an elastic coefficient (ZE) and speed ratio $(\mathrm{mG})$ as:

$$
\begin{aligned}
& Z_{E}=\left[\frac{1}{\pi\left(\frac{\left(1-v_{P}^{2}\right)}{E_{P}}+\frac{\left(1-v_{G}^{2}\right)}{E_{G}}\right)}\right]^{1 / 2}, \\
& m_{G}=\frac{N_{G}}{N_{P}}
\end{aligned}
$$

where, $N_{G}$ teeth number of the gear, $N_{P}$ teeth number of the pinion and $m_{G}$ is the speed ratio.

\section{Appendix B. AGMA stress equations}

Two fundamental stress equations are used in the AGMA methodology, one for bending stress and another for pitting resistance (contact stress). The contact stress and bending stress of gears are called "contact stress number" and "bending stress number" in AGMA standards. According to AGMA 2101-C95, the bending stress number $\sigma$ and the contact stress number $\sigma_{c}$ for involute helical gears can be determined as follows [34].

$$
\begin{aligned}
& \sigma=W^{t} K_{0} K_{V}^{\prime} K_{S} \frac{1}{b m_{i}} \frac{K_{H} K_{B}}{Y_{j}}, \\
& \sigma_{t}=Z_{E} \sqrt{W^{t} K_{0} K_{V}^{\prime} K_{S} \frac{K_{H}}{d_{\omega 1} B} \frac{Z_{R}}{Z_{I}}} .
\end{aligned}
$$

The detailed derivations and Tables of geometry factors $Z_{I}$ and $Y_{j}$ are included in AGMA 218.01 [35]. According to the design parameters of the involute helical gear 
pair listed in Table 1 , the geometry factor $Z_{I}$ is 0.104 , and the values of geometry factor $Y_{j}$ is 0.4186 for the gears.

As the FEM analysis was carried out statically and ideally, the gear loading was considered uniformly, the dynamic and overload factors was considered one.

\section{References}

1. Tsay, C. 1988. Helical gears with involute shaped teeth: geometry, computer simulation, tooth contact analysis, and stress analysis, ASME J. Mech. Transmissions Automation 482.

2. .Chen, Y.C.; Tasy, C.B. 2002. Stress analysis of a helical gear set with localized bearing contact, Finite Element Anal. Des. 38(8): 707-723. https://doi.org/10.1016/S0168-874X(01)00100-7.

3. Litvin, F. 1994. Gear Geometry and Applied Theory. NJ: Prentice-Hall.

4. Litvin, F.L.; Kim, D. H. 1997. Computerized design, generation and simulation of modified involute spur gears with localized bearing contact and reduced level of transmission errors, ASME. J. Mech. Des. 119(1): 96100.

https://doi.org/10.1115/1.2828795.

5. Litvin, F.L.; Chen, N.X.; Lu, J.; Handschuh, R.F. 1995. Computerized design and generation of low-noise helical gears with modified surface topology, ASME. J. Mech. Des. 117: 254-161.

https://doi.org/10.1115/1.2826131.

6. Litvin, F.L.; Lian, Q.; Kapelevich, A.L. 2000. Asymmetric modified spur gear drives: reduction of noise, localization of contact, simulation of meshing and stress analysis, Comput. Method Appl. Mech. Eng. 188; 363-390 https://doi.org/10.1016/S0045-7825(99)00161-9.

7. Zhang, Y.; Fang, Z. 1997. Analysis of transmission errors under load of helical gears with modified tooth gears, ASME. J. Mech. Des. 119: 120-126. https://doi.org/10.1115/1.2828773.

8. Failure analysis and prevention, ASM handbook, vol. 11., Metals Park (OH):American Society for Metals, 1986.

9. Asi, O. 2006. Fatigue failure of a helical gear in a gearbox. 13: 1116- 25. Eng Fail Anal 13: 1116-1125. https://doi.org/10.1016/j.engfailanal.2005.07.020.

10. Fatigue and fracture, ASM handbook, vol 19, American Society for Metals, 1996.

11. Arikan, M.A.S.; Tamar, M. 1992. Tooth contact and 3-D stress analysis of involute helical gears. ASME, International Power Transmission and Gearing Conference 43(2): 461-468.

12. Roa, C.R.M.; Muthuveerappan, G. 1993. Finite element modeling and stress analysis of helical gear teeth. Comput. Struct. 49(6): 1095-1106. https://doi.org/10.1016/0045-7949(93)90020-E.

13. Hedlund, J.; Lehtovaara, A. 2006. Modeling of helical gear contact with tooth deflection, Tribology International 40: 613-619. https://doi.org/10.1016/j.triboint.2005.11.004.

14. Ding, Y.; Rieger, N.F. 2003. Spalling formation mechanism for gears. Wear 254(12): 1307-1317. https://doi.org/10.1016/S0043-1648(03)00126-1.

15. [Online]. Available from: http:/www.elecon.com/gearworld/dat-gw-failure.html.

16. Flodin, A. 2000. Simulation of mild wear in helical gears, Wear 241: 123-128.

https://doi.org/10.1016/S0043-1648(00)00384-7.

17. Coy, J.J.; Chao, CH.C. 1982. A method of selecting grid size to account for Hertz deformation in finite element analysis of spur gears, J. Mech. Des. 104: 759-766, https://doi.org/10.1115/1.3256429.

18. Du, S.; Randall, R. B.; Kelly, D. W. 1998. Modeling of spur gear mesh stiffness and static transmission error, Proc Inst Mech Eng part C 212: 287-297.

19. Arafa, M.H.; Megahed, M.M. 1999. Evaluation of spur gear mesh compliance using the finite element method, Proc. Inst. Mech. Eng. part C 213: 569-579. https://doi.org/10.1243/0954406991522509.

20. Vedmar, L. 1981. On the design of external involute helical gears, Transactions of Machine Elements Division, Doctoral dissertation, Lund Technical University, Lund, Sweden, 100 p,.

21. Pimsarn, M.; Kazerounian, K. 2002. Efficient evaluation of spur gear tooth mesh load using pseudointerference stiffness estimation method., Mech. Mach. Theory 37:. 769-786. https://doi.org/10.1016/S0094-114X(02)00022-8.

22. Kawalec, A.; Wiktor, J.; Ceglarek, D. 2006. Comparative Analysis of Tooth-Root Strength Using ISO and AGMA Standards in Spur and Helical Gears With FEM-based Verification, Journal of Mechanical Design 128: 1141-1158.

https://doi.org/10.1115/1.2214735.

23. Qin, W.J.; Guan, C.Y. 2014. An investigation of contact stresses and crack initiation in spur gears basedon finite element dynamics analysis. Int. J. of Mech. Sci. 83: 96-103. https://doi.org/10.1016/j.ijmecsci.2014.03.035.

24. Barbieri, M.; Zippo, A.; Pelli-cano, F. 2014. Adaptive grid-size finite element modeling of heli-cal gear pairs, Mech. Mach. Theory 82: 17-32.

https://doi.org/10.1016/j.mechmachtheory.2014.07.009.

25. Santosh S. Patil; Saravanan, Karuppanan; Ivana, Atanasovska; Azmi, Abdul, Wahab. 2014. Contact stress analysis of helical gear pairs, including frictional coefficients, Int. J. of Mech. Sci. 85: 205-211. https://doi.org/10.1016/j.ijmecsci.2014.05.013.

26. Prabhu Sekar R.; Muthuveerappan, G. 2014. Load sharing based maximum fillet stress analysis of asymmetric helical gears designed through direct design - A parametric study, Mech. Mach. Theory 80: 84-102. https://doi.org/10.1016/j.mechmachtheory.2014.04.021

27. Sell, D.J. 1992. Finite Element Modeling Spur and Helical Gears in Contact, SAE 922440: 697-703, https://doi.org/10.4271/922440.

28. Swanson Analysis Systems Inc. ANSYS, Release 12.

29. Mao, K. 2007. Gear tooth contact analysis and its application in the reduction of fatigue wear, Wear 262: 1281-1288. https://doi.org/10.1016/j.wear.2006.06.019.

30. Aziz, S.; Chassapis, C. 2002. Knowledge-based Geometry Generation for Spur and Helical Gears, Concurrent Engineering 10(3): 251-261. https://doi.org/10.1177/106329302761689160.

31. Fernandes, P.J.L 1996. Tooth bending fatigue in gears, Eng Fail Anal 3: 219-225. https://doi.org/10.1016/1350-6307(96)00008-8. 
32. Shigley, J.E.; Mischke, C.R. 2001. Mechanical engineering design, McGraw-Hill,Sixth edition: 145919.

33. Fajdiga, G.; Glode, S.; Kramar, J. 2007. Pitting formation due to surface and subsurface initiated fatigue crack growth in contacting mechanical elements, Wear 262: 1217-1224.

https://doi.org/10.1016/j.wear.2006.11.016.

34. American Gear Manufacturers Association, AGMA 2101-C95, Fundamental rating factors and calculation methods for involute spur and helical gear teeth, U.S.A, 1994.

35. American Gear Manufacturers Association, AGMA 218.01., Fundamental rating factors and calculation methods for involute spur and helical gears, U,S,A, 1982.
M. Gh. Khosroshahi, A. M. Fattahi

\section{THREE DIMENSIONAL STRESS ANALYSIS OF A HELICAL GEAR DRIVE WITH FINITE ELEMENT METHOD}

S u m m a r y

Helical gears are widely used as power transmitting gears between parallel or crossed shafts in gearbox or other parts of machine, since not only can they carry large load but also the noise level experienced during the operation is low. The application of parallel axis helical gears is well established in gear industry. So stress analysis of involute-helical gears is very beneficial and has specific importance. However, due to their shape complexity using analytical method to solve and gain stress distributions at engaged teeth is very difficult task. To facilitate the convergency different types of elements has been used for the contacting surfaces and the rest of the model, respectively. In this paper, the distribution of contact stresses, bending stresses and torque transmission in the pinion for a given tangential displacement (rotation) of the pinion hole surface was investigated using FEM and the obtained stresses are then compared with Hertz theory and AGMA standard.

Keywords: helical gear; FEM; bending stress; contact stress; Hertz theory; AGMA standard.

Received May 01, 2016

Accepted October 13, 2017 